・研究报告・

\title{
北京近郊深土层动物群落结构特征
}

\author{
莫 畏 1,2 王志良 ${ }^{2}$ 李 猷 ${ }^{2}$ 郭建军 $1,2^{*}$ 张润志 ${ }^{2,3 *}$ \\ 1 (贵州大学昆虫研究所, 贵阳 550025) \\ 2 (中国科学院动物研究所, 北京 100101) \\ 3 (中国科学院大学, 北京 100049)
}

\begin{abstract}
摘要: 为了解城市近郊深层土壤中动物群落结构组成, 2012年在北京市北四环和北五环之间的中国科学院奥运村 科技园区埋设陷阱收集器, 对地下 $30 \mathrm{~cm}$ 和 $55 \mathrm{~cm}$ 土层活动的动物进行采样。2013-2017年8次调查共捕获动物3门10 纲20目 10,163 头, 优势类群分别是膜翅目 $(61.0 \%)$ 、蜱螨目(12.1\%)和弹尾目 $(11.2 \%) 。 30 \mathrm{~cm}$ 土层动物类群数和个体 数均高于 $55 \mathrm{~cm}, 30 \mathrm{~cm}$ 土层优势类群为膜翅目(69.4\%), $55 \mathrm{~cm}$ 土层优势类群除膜翅目 (45.7\%)外还有蜱螨目 $(21.8 \%)$ 和弹尾目(16.4\%)。夏秋季动物个体数和类群数高于冬春季, 环节动物门仅出现于冬春季, 而缨翅目、啮虫目和革 翅目仅出现于夏秋季。不同绿化带类型间动物群落Jaccard相似性指数均高于 0.75 , Shannon-Wiener多样性指数、 Simpson优势度指数和Pielou均匀度指数均不存在显著性差异 $(P>0.05)$ 。结果表明: 深层土壤中存在着大量的动物 类群, 动物个体数和类群数均随土层加深而减少。不同季节人工绿地土壤中动物结构存在差异, 而不同植被类型 下动物群落组成高度相似。
\end{abstract}

关键词: 土壤动物; 群落结构; 土壤深层; 多样性; 人工绿地

\section{Faunal communities of deep soil layers in suburban Beijing}

\author{
Wei Mo ${ }^{1,2}$, Zhiliang Wang ${ }^{2}$, You $\mathrm{Li}^{2}$, Jianjun Guo ${ }^{1,2^{*}}$, Runzhi Zhang ${ }^{2,3^{*}}$ \\ 1 Institute of Entomology, Guizhou University, Guiyang 550025 \\ 2 Institute of Zoology, Chinese Academy of Sciences, Beijing 100101 \\ 3 University of Chinese Academy of Sciences, Beijing 100049
}

\begin{abstract}
In order to reveal composition of faunal communities in deep soil, we investigated soil at 30 and $55 \mathrm{~cm}$ at the Olympic Campus of the Chinese Academy of Sciences in a suburb of Beijing using trap collectors. A total of 10,163 individuals representing 20 orders belonging to ten classes and three phyla were captured in eight surveys carried out over five years. The dominant groups were Hymenoptera (61.0\%), Acarina (12.1\%) and Collembola (11.2\%). The individuals and groups in the $30 \mathrm{~cm}$ soil layer were greater than at 55 $\mathrm{cm}$. The dominant group of the $30 \mathrm{~cm}$ soil layer was Hymenoptera (69.4\%) while at $55 \mathrm{~cm}$, Hymenoptera (45.7\%), Acarina (21.8\%) and Collembola (16.4\%) were all dominant. The number of individuals and groups recorded from April to October was greater than October to April of the next year. Annelida appeared only between October to April of the next year, while Thysanoptera, Psocoptera, Dermaptera appeared only between April to October. The lowest Jaccard value of soil faunal communities in different vegetation forms was 0.75. None of Shannon-Wiener diversity index, Simpson dominance index and Pielou evenness index showed significant differences between different vegetation types $(P>0.05)$. The results showed that there were abundant soil faunal communities in deep soil. The number of individuals and groups decreased with increasing soil depth. Soil faunal community structure was different in different seasons and the composition was highly similar between different vegetation types.
\end{abstract}

Key words: soil animal; community structure; deep soil; diversity; treelawn

收稿日期: 2018-01-29; 接受日期: 2018-03-23

*共同通讯作者 Co-authors for correspondence. E-mail: jjguo@gzu.edu.cn; zhangrz@ioz.ac.cn 
土壤动物是指全部或部分生活史在土壤或调 落物中度过, 而且对土壤有一定影响的无脊椎动物 (尹文英, 1998), 具有指示环境质量, 维持养分循环 等诸多重要生态功能, 是土壤生态系统食物网中不 可分割的组成部分(Bongers \& Ferris, 1999)。目前 对 土壤生物多样性的研究和认识越来越深入, 土壤已 被科学界认为是地球上生物多样性最丰富的生境 (Coleman \& Whitman, 2005; Wall et al, 2012; Powell et al, 2014)。研究表明每平方米的土壤中跳虫密度 最高可达67万头(Petersen \& Luxton, 1982); 仅土壤 甲虫, 已命名的就有4万多种(Lovei \& Sunderland, 1996); 数据显示, 全球被描述过的物种数中土壤动 物占23\% (Decaëns et al, 2006)。

然而城市的快速发展伴随着城市绿地缩减, 土 地利用方式等环境变化, 不断扩大的城市道路和人 工建筑等硬化物覆盖了原有的土壤，阻碍了土壤与 外界的能量物质交换, 严重威胁着城市生物多样性 (Rebele, 1994; Mckinney, 2008)。由城市环境变化造 成的物种丧失及生物多样性下降问题已经引起了 人们的高度重视, 已有研究表明城市地表硬化后土 壤动物类群数与个体数明显低于草地 (宋英石等, 2015), 公园土壤动物丰富度明显高于住宅区(彭涛等, 2006)。相较农田和草地而言, 林地土壤动物群落多 样性指数更高(章家恩等, 2011)。在垂直方向上, 普遍 认为土壤动物群落具有明显的表聚性, 这在自然生 态系统中表现尤为明显。例如大型土壤动物群落越 靠近表层数量越大(殷秀琴, 2001; 傅必谦等, 2002), 但是不同季节表聚程度有一定差异(李伟等, 2015)。

虽然土壤具有极其丰富的物种多样性, 但是受 研究手段限制, 关于土壤动物的研究工作还很不完 善。目前土壤动物的取样方法主要是直接取土, 然 后用手拣或漏斗分离土壤动物的传统方式, 这样的 取样方法过程复杂且工作量大，在很大程度上限制 了土壤动物的研究(Andre et al, 2002)。我们参考西 班牙人研究火山口土壤生物的收集装置(López \& Oromí, 2010), 制作了可收集地下深层土壤动物的 收集器, 并用于城市深土层动物群落的研究, 以期 了解城市近郊深土层动物群落结构组成, 同时也希 望能为国内土壤动物研究提供新的思路和方法。

\section{研究区域}

研究区域位于北京市四环路与五环路之间的
朝阳区北辰西路西侧中国科学院奥运村科技园区 $\left(40^{\circ} 00^{\prime} 07^{\prime \prime} \mathrm{N}, 116^{\circ} 22^{\prime} 33^{\prime \prime} \mathrm{E}\right)$, 海拔48 m, 年均降雨 量626 mm, 土壤结构复杂, 扰动频繁, 主要为城市 建设过程中垫铺的碴土和田园土。园区内分布着 10 多个大型人工建筑群，道路硬化严重，属于人类活 动频繁、城市化程度较高的区域。根据绿化带内种 植的植物将其分为 4 种类型。

草本型: 绿化带内全部为草本植物, 主要为细 叶结缕草(Zoysia tenuifolia), 面积 $20 \mathrm{~m} \times 20 \mathrm{~m}$, 植 被盖度100\%。

灌木型：绿化带内包含草本植物和灌木, 主要 为细叶结缕草、黄杨 (Buxus sinica) 和紫叶小檗 (Berberis thunbergii var. atropurpurea)。面积100 m × $5 \mathrm{~m}$ ，草本和灌木各占 $1 / 2$ ，植被覆盖度 $100 \%$ 。

乔木型：绿化带内包含草本植物和乔木，主要 为细叶结缕草和银杏(Ginkgo biloba)。面积 $100 \mathrm{~m} \times$ $5 \mathrm{~m}$ ，草本和乔木各占 $1 / 2$ ，植被覆盖度 $100 \%$ 。

混合型：绿化带内包含草本植物、灌木和乔木, 主要为细叶结缕草、黄杨、紫叶小檗、银杏、玉兰 (Magnolia denudate)和臭椿(Ailanthus altissima)。面 积 $20 \mathrm{~m} \times 20 \mathrm{~m}$ ，植被覆盖度 $60 \%$ 。

\section{研究方法}

\section{1 采样装置}

收集器: $30 \mathrm{~cm}$ 土层动物收集器包括PVC圆柱 管(高 $45 \mathrm{~cm}$, 直径 $15 \mathrm{~cm}$ )、绑有金属线的圆柱形标本 容器(高15 cm, 直径 $14 \mathrm{~cm}$ )和镶嵌铁环的盖子(高 $5 \mathrm{~cm}$, 直径 $16 \mathrm{~cm})$, 距PVC管管口 $25 \mathrm{~cm}$ 处打有 8 个 直径为 $2 \mathrm{~cm}$ 的小孔。 $55 \mathrm{~cm}$ 土层动物收集器包括PVC 圆柱管(高70 cm, 直径 $15 \mathrm{~cm}$ )、绑有金属线的圆柱形 标本容器(高 $15 \mathrm{~cm}$, 直径 $14 \mathrm{~cm}$ )和镶嵌铁环的盖子 (高5 cm, 直径 $16 \mathrm{~cm}$ ), 距PVC管管口50 cm处打有 8 个直径为 $2 \mathrm{~cm}$ 的小孔(图1)。

埋设方法: 根据收集器的大小, 使用螺旋打孔 机在土壤中打恰好能容纳收集器的洞。在标本容器 中加入 $200 \mathrm{~mL}$ 的过饱和盐水, 并置于PVC管底部, 盖上盖子，将整个装置放入洞中，并保证铁环顶部 与地平面在一个水平面上, 最后盖上薄土。装置埋 好后, GPS精确记录经纬度, 相机多角度拍摄记录 收集器周围环境, 以便收集器的寻找。收集标本时 根据收集器埋置记录的样地经纬度及照片找到样 地, 用金属探测器探测地面, 感应到金属吊环, 即 


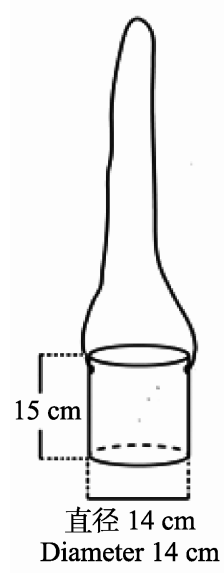

图1 样本收集器

Fig. 1 Trap collector of samples

是收集器的位置所在。

深土层动物收集原理：收集器埋放于土壤中, 动物从收集器小孔穿过时掉入盛有过饱和食盐水的 标本容器中, 达到收集土壤中动物标本的目的。

\section{2 取样和鉴定}

每种绿化带类型选取3个样点, 每个样点埋设 1 个30 cm 土层动物收集器和 1 个 $55 \mathrm{~cm}$ 土层动物收集 器, 收集器之间间隔 $2 \mathrm{~m}$, 共埋设了 24 个。所有收集 器于2012年10月前埋设完毕，之后每年4月和10月 取样。4月样品代表10月以后和4月之前动物的活动 情况, 收集器在野外放置的时间段为第一年10月到 第二年的 4 月, 主要处于冬季和春季。而10月代表 4-10月之间动物活动情况, 收集器在野外放置的时 间段为当年 4 月到 10 月, 主要处于夏季和秋季, 属 于植物的生长季。2013-2017年上半年, 共调查了8 次(2016年只于10月调查了1次)。每次收样时先打开 收集器盖子, 取出标本容器, 将容器里的所有标本 转移到塑封袋内, 换新的过饱和食盐水, 重新掩 埋。收集到的标本带回实验室除去泥沙, 保存于 $100 \%$ 的酒精溶液, 存放于 $-40^{\circ} \mathrm{C}$ 冰箱中。最后在体 视显微镜下进行动物的鉴定, 主要参考《中国土壤 动物检索图鉴》(尹文英, 1998) 和《昆虫分类学》(袁 锋, 2006), 所有标本鉴定到目。

\section{3 数据分析}

多样性分析采用以下几个指数:
(1) Shannon-Wiener 多样性指数 (Shannon \& Weaver, 1949):

$H^{\prime}=-\Sigma P_{i} \ln P_{i}$

(2) Pielou均匀度指数(Pielou, 1985):

$E=H^{\prime} / \ln S$

(3) Simpson优势度指数(Simpson, 1949):

$C=\Sigma\left(n_{i} / N\right)^{2}$

式中, $P_{i}$ 为 $i$ 类群个体数占类群总个体数的比例, $n_{i}$ 为 该区内第 $\mathrm{i}$ 个类群的个体数量, $N$ 为样区内所有类群 的个体数量, $S$ 为类群数。

相似性采用Jaccard指数(Jaccard, 1912):

$q=\mathrm{c} /(a+b-c)$

式中, $a 、 b$ 分别为群落 $\mathrm{A} 、 \mathrm{~B}$ 的类群数, $c$ 为两类群的 共有类群数。Jaccard指数计算值在 $0.75-1.00$ 为极相 似，0.50-0.74为中等相似，0.25-0.49为中等不相似， 0-0.24为极不相似。

定义个体数大于 $10 \%$ 的为优势类群, $1-10 \%$ 的 为常见类群, 小于 $1 \%$ 的为稀有类群 (傅必谦等, 2002)。

数据处理和分析使用R-3.4.3 (vegan) 及Microsoft Excel 2016。

\section{3 结果}

\section{1 深土层动物群落组成}

2013-2017年8次调查共捕获动物3门10纲20目 
10,163 头, 分别是软体动物门、环节动物门和节肢 动物门3门, 昆虫纲、蛛形纲、唇足纲、倍足纲、软 甲纲、弹尾纲、双尾纲、综合纲、塞毛纲及腹足纲 10 纲, 膜翅目、同翅目、鞘翅目、双翅目、半翅目、 直翅目、紧翅目、啮虫目、革翅目、石蜈蚣目、地 蜈蚣目、蜱螨目、蜘蛛目、带马陆目、等足目、双 尾目、弹尾目、综合目、柄眼目和后孔寡毛目20目。 其中节肢动物门 8 纲 18 目, 昆虫纲 9 目, 分别是门和 纲上类群数最多的类群(表1)。

节肢动物门有 10,084 头，占总个体数的 $99.2 \%$, 为门水平上的优势类群, 软体动物门和环节动物门 为稀有类群，仅占 $0.8 \%$ 。纲水平上，优势类群为昆 虫纲、蛛形纲和弹尾纲, 分别占 $69.8 \% 、 12.9 \%$ 和 $11.2 \%$; 常见类群为唇足纲、双尾纲和软甲纲, 分别 占 $1.8 \% 、 1.6 \%$ 和 $1.4 \%$; 稀有类群占 $1.4 \%$, 分别是倍 足纲、综合纲、腹足纲和寡毛纲。目水平上, 膜翅 目、蜱螨目和弹尾目为优势类群，分别占 $61.0 \%$ 、 $12.1 \%$ 和 $11.2 \%$; 同翅目、双翅目、鞘翅目、双尾目、 石蜈蚣目和等足目 6 个类群为常见类群，分别占总 个体数的 $3.1 \% 、 3.1 \% 、 2.1 \% 、 1.6 \% 、 1.4 \%$ 和 $1.4 \%$ 。 稀有类群共 11 个, 即半翅目、直翅目、缨翅目、啮 虫目、革翅目、地蜈蚣目、蜘蛛目、带马陆目、综 合目、柄眼目和后孔寡毛目，稀有类群仅占 $3.1 \%$ (表 1)。

\section{2 两种土层动物群落组成比较}

$30 \mathrm{~cm}$ 与 $55 \mathrm{~cm}$ 土层动物群落组成上有所差异, $30 \mathrm{~cm}$ 土层动物隶属节肢动物门、软体动物门和环 节动物门 3 个门, $55 \mathrm{~cm}$ 土层动物隶属节肢动物门和 软体动物门。纲水平上, $30 \mathrm{~cm}$ 土层动物隶属昆虫 纲、蛛形纲等 10 个纲, 而 $55 \mathrm{~cm}$ 土层动物隶属 9 个纲, 寡毛纲仅出现于 $30 \mathrm{~cm}$ 土层。在目水平上, $30 \mathrm{~cm}$ 土 层由 19 个类群构成, $55 \mathrm{~cm}$ 土层由 17 个类群组成, 啮 虫目、革翅目和后孔寡毛目仅出现于 $30 \mathrm{~cm}$ 土层, 紧 翅目仅出现于 $55 \mathrm{~cm}$ 土层。

$30 \mathrm{~cm}$ 和 $55 \mathrm{~cm}$ 土层动物优势类群的组成在门 水平上相同，均为节肢动物门(98.6\%和 $99.5 \%)$, 纲 水平以下有所差异。纲水平上, $30 \mathrm{~cm}$ 土层优势类群 为昆虫纲(78.9\%), 而55 cm土层优势类群除了昆虫 纲(53.3\%)外还有蛛形纲(23.0\%)及弹尾纲(16.4\%)。 目水平上, $30 \mathrm{~cm}$ 土层优势类群为膜翅目 (69.4\%), $55 \mathrm{~cm}$ 土层除膜翅目 (45.7\%) 外还有蜱螨目 (21.8\%)
和弹尾目 $(16.4 \%)$ 。 $30 \mathrm{~cm}$ 土层动物常见类群 7 个, 分 别是同翅目、鞘翅目、双翅目、石蜈蚣目、蜱螨目、 弹尾目、双尾目和等足目; $55 \mathrm{~cm}$ 土层动物常见类群 6 个, 分别是鞘翅目、双翅目、石蜈蚣目、蜘蛛目、 双尾目和等足目; 蜘蛛目为 $30 \mathrm{~cm}$ 土层的稀有类群, 在55 cm土层却为常见类群, 同翅目为 $30 \mathrm{~cm}$ 土层中 的常见类群, 在 $55 \mathrm{~cm}$ 中却为稀有类群(表1)。

从总的个体数和类群数上看, $30 \mathrm{~cm}$ 土层(个体 数6,547, 类群数 19)均高于 $55 \mathrm{~cm}$ 土层(个体数 3,616 , 类群数 17)。土壤动物个体数和类群数随土层加深而 减少, 说明深土层动物具有表聚现象。

\section{3 深土层动物群落季节动态}

使用2013-2015年的数据分析动物群落季节动 态(表2)。冬春季和夏秋季动物类群构成不同，冬春 季深土层动物由节肢动物门、环节动物门和软体动 物门 3 个门构成, 夏秋季由节肢动物门和软体动物 门构成。纲的组成上，冬春季动物由昆虫纲等10个 纲组成, 夏秋季由 9 个纲组成, 寡毛纲仅出现在冬 春季。目的组成上，夏秋季(19目)高于冬春季(17目), 缨翅目、啮虫目和革翅目仅出现于夏秋季，后孔寡 毛目仅出现于冬春季。从个体数上看, 夏秋季 $(5,338$ 头)高于冬春季, 约为冬春季的1.8倍。优势类群、常 见类群及稀有类群的构成不同，冬春季优势类群为 膜翅目 (48.7\%)、弹尾目 (18.9\%)和蜱螨目 (14.0\%), 常见类群为双翅目 $(5.0 \%)$ 、同翅目 $(3.9 \%)$ 、鞘翅目 (2.9\%)、等足目 $(1.8 \%)$ 、双尾目 $(1.3 \%)$ 和石蜈蚣目 (1.1\%)等6个, 其他 8 个为稀有类群 $(2.3 \%)$ 。夏秋季优 势类群为膜翅目 $(69.7 \%)$ 和蜱螨目 $(10.7 \%)$, 常见类 群为弹尾目 $(5.0 \%)$ 、双翅目 $(2.9 \%)$ 、同翅目 $(2.7 \%)$ 、 等足目 $(1.7 \%)$ 、鞘翅目 $(1.4 \%)$ 、石蜈蚣目 $(1.4 \%)$ 和双 尾目 $(1.4 \%)$ 等 7 个, 稀有类群有 10 个目, 个体数占 $3.1 \%$ 。

\section{4 不同绿化带类型深土层动物群落比较}

乔木型优势类群为膜翅目, 其他类型的优势类 群均为膜翅目、蜱螨目和弹尾目。啮虫目仅出现在 草本型，革翅目仅出现于乔木型，缨翅目仅出现于 混合型。草本型中杂食性个体数 $(85.7 \%)>$ 捕食性 (6.9\%) > 腐食性 $(3.1 \%)>$ 枯食性 $(2.8 \%)>$ 植食性 (1.4\%); 灌木型杂食性(82.5\%) > 捕食性(6.8\%) > 腐食性(5.6\%) > 枯食性(3.0\%) > 植食性(2.3\%); 乔 木型中杂食性个体数 $(85.0 \%)>$ 腐食性 $(8.2 \%)>$ 捕 


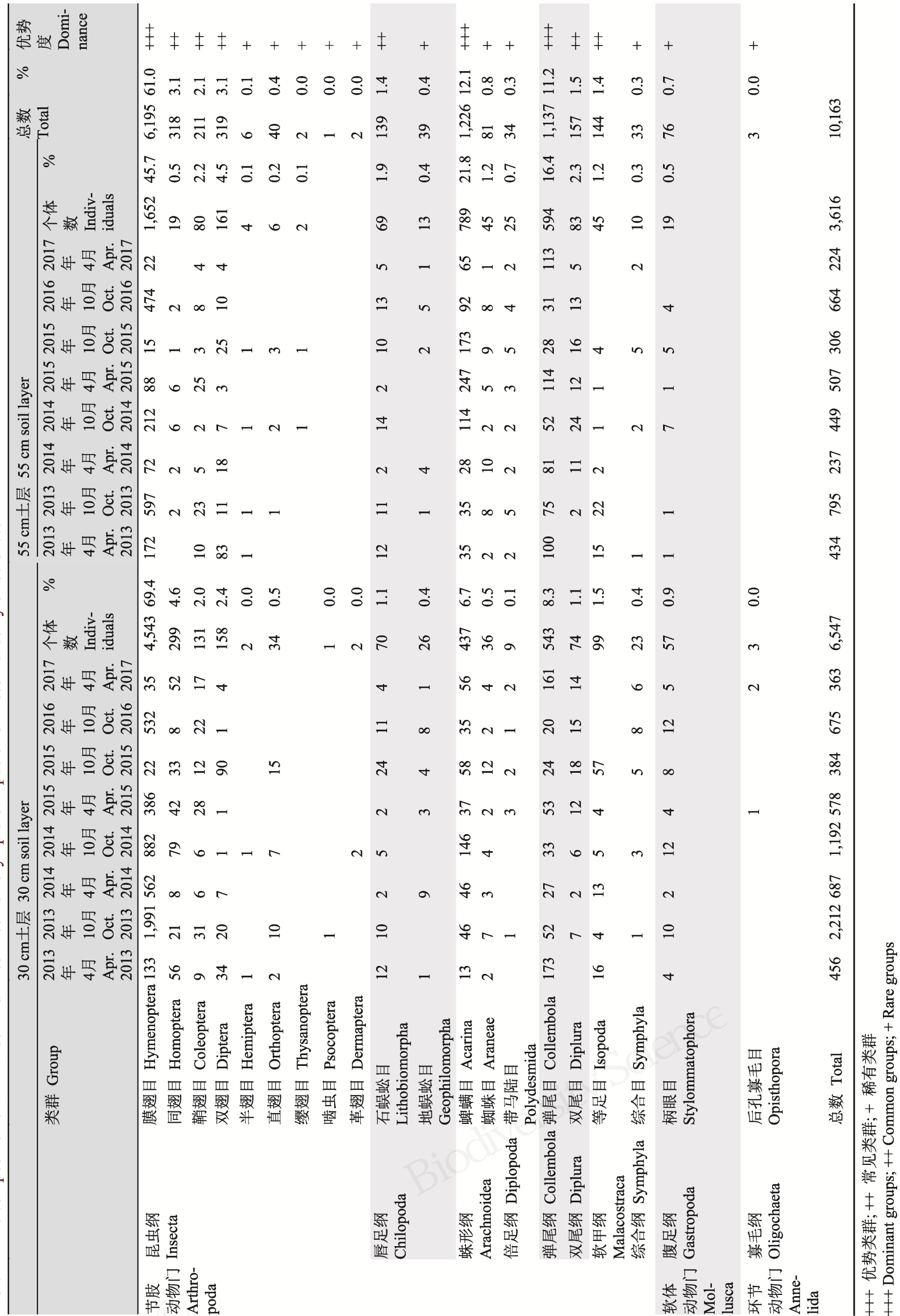


表2 中国科学院奥运村科技园不同季节深土层动物群落组成

Table 2 The composition of animal communities of deep soil layer in different seasons of Olympic Campus of Chinese Academy of Sciences

\begin{tabular}{|c|c|c|c|c|c|c|}
\hline & \multicolumn{3}{|c|}{ 夏秋季 April to October } & \multicolumn{3}{|c|}{ 冬春季 October to April of the next year } \\
\hline & $\begin{array}{l}\text { 个体数 } \\
\text { Individuals }\end{array}$ & $\%$ & $\begin{array}{l}\text { 优势度 } \\
\text { Dominance } \\
\end{array}$ & $\begin{array}{l}\text { 个体数 } \\
\text { Individuals }\end{array}$ & $\%$ & $\begin{array}{l}\text { 优势度 } \\
\text { Dominance }\end{array}$ \\
\hline 膜翅目 Hymenoptera & 3,719 & 69.7 & +++ & 1,413 & 48.7 & +++ \\
\hline 同翅目 Homoptera & 142 & 2.7 & ++ & 114 & 3.9 & ++ \\
\hline 鞘翅目 Coleoptera & 77 & 1.4 & ++ & 83 & 2.9 & ++ \\
\hline 双翅目 Diptera & 154 & 2.9 & ++ & 146 & 5 & ++ \\
\hline 半翅目 Hemiptera & 4 & 0.1 & + & 2 & 0.1 & + \\
\hline 直翅目 Orthoptera & 38 & 0.7 & + & 2 & 0.1 & + \\
\hline 缨翅目 Thysanoptera & 2 & 0 & + & & & \\
\hline 啮虫目 Psocoptera & 1 & 0 & + & & & \\
\hline 革翅目 Dermaptera & 2 & 0 & + & & & \\
\hline 石蜈蚣目 Lithobiomorpha & 74 & 1.4 & ++ & 32 & 1.1 & ++ \\
\hline 地蜈蚣目 Geophilomorpha & 7 & 0.1 & + & 17 & 0.6 & + \\
\hline 蜱螨目 Acarina & 572 & 10.7 & +++ & 406 & 14 & +++ \\
\hline 蜘蛛目 Araneae & 42 & 0.8 & + & 24 & 0.8 & + \\
\hline 带马陆目 Polydesmida & 15 & 0.3 & + & 10 & 0.3 & + \\
\hline 弹尾目 Collembola & 264 & 4.9 & ++ & 548 & 18.9 & +++ \\
\hline 双尾目 Diplura & 73 & 1.4 & ++ & 37 & 1.3 & ++ \\
\hline 等足目 Isopoda & 93 & 1.7 & ++ & 51 & 1.8 & ++ \\
\hline 综合目 Symphyla & 16 & 0.3 & + & 1 & 0 & + \\
\hline 柄眼目 Stylommatophora & 43 & 0.8 & + & 12 & 0.4 & + \\
\hline 后孔寡毛目 Opisthopora & & & & 1 & 0 & + \\
\hline 总数 Total & 5,338 & & & 2,899 & & \\
\hline
\end{tabular}

+++ 优势类群; ++ 常见类群; + 稀有类群

+++ Dominant groups; ++ Common groups; + Rare groups

食性 $(4.9 \%)>$ 植食性 $(1.3 \%)>$ 腐食性 $(0.6 \%)$; 混合 型杂食性个体数 $(94.5 \%)>$ 捕食性 $(2.4 \%)>$ 腐食性 $(1.5 \%)>$ 植食性 $(1.3 \%)>$ 枯食性 $(0.5 \%)$ 。各绿化带 类型中杂食性动物所占比例均为最高, 植食性相对 较少(表3)。

不同类型绿化带中个体数排列顺序为乔木型 (394.3) > 灌木型(351.6) > 混合型(326.6) > 草本型 (197.9)。类群数排列顺序为灌木型 $(12)>$ 混合型 (11) = 草本型(11) > 乔木型(10) (图2)。ShannonWiener多样性指数从高到低依次为灌木型(1.49) > 草本型(1.44) > 混合型(1.20) > 乔木型(1.10)。Simpson优势度指数由高到低依次为草本型 $(0.64)>$ 灌 木型 $(0.63)>$ 混合型 $(0.52)>$ 乔木型(0.49)。Pielou 均匀度指数由高到低依次是草本型 $(0.63)>$ 灌木型 $(0.60)>$ 混合型 $(0.51)>$ 乔木型 $(0.48)$ 。统计分析表 明各植被类型间的Shannon-Wiener多样性指数、
Simpson优势度指数和Pielou均匀度指数均无显著 差异 $(P>0.05)$ 。相似性计算结果显示各生境间的相 似性指数较高, 最低值为 0.75 , 出现于混合型与草 本型间及混合型与灌木型间; 最高值为 0.83 , 出现 于乔木型与草本型间及乔木型与灌木型间(表4)。

\section{讨论}

我们整理北京市近年土壤动物多样性调查, 结 果表明这些研究均为 $0-15 \mathrm{~cm}$ 的土层, $30 \mathrm{~cm}$ 以下的 深土层动物未有涉及; $0-15 \mathrm{~cm}$ 土层动物包括节肢 动物门、环节动物门、线虫动物门、软体动物门和 缓步动物门(傅必谦等, 2002; 陈国孝和宋大祥, 2000; 林英华等, 2006)。本文研究结果显示深层土 壤中也存在着包括节肢动物门、软体动物门和环节 动物门在内的大量动物群落。 $30 \mathrm{~cm}$ 土层动物隶属 3 个门, $55 \mathrm{~cm}$ 土层隶属 2 个门, 不同深度土层动物的 
表3 中国科学院奥运村科技园不同类型绿化带中深土层动物类群组成

Table 3 The composition of animal communities of deep soil layer in different treelawn of Olympic Campus of Chinese Academy of Sciences

\begin{tabular}{|c|c|c|c|c|c|c|c|c|c|c|c|c|c|}
\hline \multirow{2}{*}{$\begin{array}{l}\text { 类群 } \\
\text { Group }\end{array}$} & \multicolumn{3}{|c|}{ 草本型 Lawn } & \multicolumn{3}{|c|}{ 灌木型 Shrubbery } & \multicolumn{3}{|c|}{ 乔木型 Arboreal forest } & \multicolumn{3}{|c|}{ 混合型 Mixed forest } & \multirow{2}{*}{$\begin{array}{l}\text { 食性 } \\
\text { Feeding } \\
\text { habit }\end{array}$} \\
\hline & $\begin{array}{l}\text { 个体数 } \\
\text { Indivi- } \\
\text { duals }\end{array}$ & $\%$ & $\begin{array}{l}\text { 优势度 } \\
\text { Domi- } \\
\text { nance }\end{array}$ & $\begin{array}{l}\text { 个体数 } \\
\text { Indivi- } \\
\text { duals }\end{array}$ & $\%$ & $\begin{array}{l}\text { 优势度 } \\
\text { Domi- } \\
\text { nance }\end{array}$ & $\begin{array}{l}\text { 个体数 } \\
\text { Indivi- } \\
\text { duals }\end{array}$ & $\%$ & $\begin{array}{l}\text { 优势度 } \\
\text { Domi- } \\
\text { nance }\end{array}$ & $\begin{array}{l}\text { 个体数 } \\
\text { Indivi- } \\
\text { duals }\end{array}$ & $\%$ & $\begin{array}{l}\text { 优势度 } \\
\text { Domi- } \\
\text { nance }\end{array}$ & \\
\hline 膜翅目 Hymenoptera & 778 & 49.1 & +++ & 1,397 & 49.7 & +++ & 1,732 & 66.3 & +++ & 2,288 & 72.5 & +++ & $\mathrm{O}$ \\
\hline 同翅目 Homoptera & 67 & 4.2 & ++ & 129 & 4.6 & ++ & 113 & 4.3 & ++ & 9 & 0.3 & + & $\mathrm{O}$ \\
\hline 鞘翅目 Coleoptera & 52 & 3.3 & ++ & 60 & 2.1 & ++ & 69 & 2.6 & ++ & 30 & 1 & ++ & $\operatorname{Pr}$ \\
\hline 双翅目 Diptera & 24 & 1.5 & ++ & 55 & 2 & ++ & 210 & 8 & ++ & 30 & 1 & ++ & S \\
\hline 半翅目 Hemiptera & 2 & 0.1 & + & 2 & 0.1 & + & & & & 2 & 0.1 & + & $\mathrm{Ph}$ \\
\hline 直翅目 Orthoptera & 4 & 0.3 & + & 3 & 0.1 & + & 16 & 0.6 & + & 17 & 0.5 & + & $\mathrm{Ph}$ \\
\hline 缨翅目 Thysanoptera & & & & & & & & & & 2 & 0.1 & + & $\mathrm{Ph}$ \\
\hline 啮虫目 Psocoptera & 1 & 0.1 & + & & & & & & & & & & $\mathrm{Ph}$ \\
\hline 革翅目 Dermaptera & & & & & & & 2 & 0.1 & + & & & & $\mathrm{O}$ \\
\hline 石蜈蚣目 Lithobiomorpha & 29 & 1.8 & ++ & 65 & 2.3 & ++ & 26 & 1 & ++ & 19 & 0.6 & + & $\operatorname{Pr}$ \\
\hline 地蜈蚣目 Geophilomorpha & 7 & 0.4 & + & 24 & 0.9 & + & 3 & 0.1 & + & 5 & 0.2 & + & $\operatorname{Pr}$ \\
\hline 蜱螨目 Acarina & 230 & 14.5 & +++ & 511 & 18.2 & +++ & 138 & 5.3 & ++ & 347 & 11 & +++ & $\mathrm{O}$ \\
\hline 蜘蛛目 Araneae & 6 & 0.4 & + & 38 & 1.4 & ++ & 27 & 1 & ++ & 10 & 0.3 & + & $\operatorname{Pr}$ \\
\hline 带马陆目 Polydesmida & 2 & 0.1 & + & 14 & 0.5 & + & 13 & 0.5 & + & 5 & 0.2 & + & $\mathrm{Ph}$ \\
\hline 弹尾目 Collembola & 283 & 17.9 & +++ & 282 & 10 & +++ & 235 & 9 & ++ & 337 & 10.7 & +++ & $\mathrm{O}$ \\
\hline 双尾目 Diplura & 44 & 2.8 & ++ & 83 & 3 & ++ & 15 & 0.6 & + & 15 & 0.5 & + & $\mathrm{D}$ \\
\hline 等足目 Isopoda & 25 & 1.6 & ++ & 100 & 3.6 & ++ & 5 & 0.2 & + & 14 & 0.4 & + & S \\
\hline 综合目 Symphyla & 16 & 1 & ++ & 4 & 0.1 & + & 5 & 0.2 & + & 8 & 0.3 & + & $\operatorname{Pr}$ \\
\hline 柄眼目 Stylommatophora & 13 & 0.8 & + & 45 & 1.6 & ++ & 4 & 0.2 & + & 14 & 0.4 & + & $\mathrm{Ph}$ \\
\hline 后孔寡毛目 Opisthopora & & & & 1 & 0 & + & & & & 2 & 0.1 & + & $\mathrm{S}$ \\
\hline 总数 Total & 1,583 & & & 2,813 & & & 2,613 & & & 3,154 & & & \\
\hline
\end{tabular}

+++ 优势类群; ++ 常见类群; + 稀有类群。Ph: 植食性; D: 枯食性; Pr: 捕食性; S: 腐食性; O: 杂食性。

+++ Dominant groups; ++ Common groups; + Rare groups. Ph, Phytophage; D, Debris feeder; Pr, Predatory; S, Saprophagy; O, Omnivores.

构成在门水平上就有差异, 随着土层加深动物门数 减少。从总体上看, 0-55 cm 土层动物在类群上具有 一定的表聚性, 这与大多数学者的研究结论相似。 调查地深土层分布大量动物可能与土壤扰动有关, 部分动物类群向下迁移躲避因土壤扰动带来的不 利影响。

蝶蚓是土壤质量变化的重要指示生物, 对温度 变化极为敏感(Decaëns et al, 1999), 其呼吸严重依 赖水分, 喜欢有机物质丰富的环境(Rombke et al, 2005), 在非城市区域一般作为常见类群(陈国孝和 宋大祥, 2000; 林英华等, 2006), 本研究捕获的蚟蚓 个体数明显低于非城市区域, 这很可能是调查地覆 盖的大量硬化道路及人工建筑造成的, 地表硬化后 土壤与外界隔绝, 土壤内部与外界无法进行物质交 换限制了虾蚓扩散, 同时土壤温度显著升高, 不利
于蚟蚓的生存(宋英石等, 2015)。此外, 本次调查地 原来是农业活动频繁的农场，与其他动物相比，蚳 蚓更容易受农药化肥施用的影响(王移等，2010)。

在北京市郊区土壤动物的研究中, 优势类群为 蜱螨目和弹尾目(傅必谦等, 2002; 陈国孝和宋大祥, 2000; 林英华等, 2006), 这与本文研究结果(优势类 群为膜翅目、蜱螨目和弹尾目，且膜翅目占 $60 \%$ 以 上)有所差异，可以看出城市区域膜翅目所占比例 更大。其原因可能有：(1)城市化对膜翅目蚁科的影 响小于蜱螨目和弹尾目, 且已有研究表明城市区域 中栖息地的缩减不会影响膜翅目蚂蚁的丰富度 (Gibb \& Hochuli，2002); (2)蚂蚁相对于螨和跳虫, 活动能力较强, 更容易到达较深的土层, 同时由于 收集器长时间埋设于地下, 标本的收集是个累积的 过程, 动物活动越频繁掉入陷阱的概率越大, 可能 

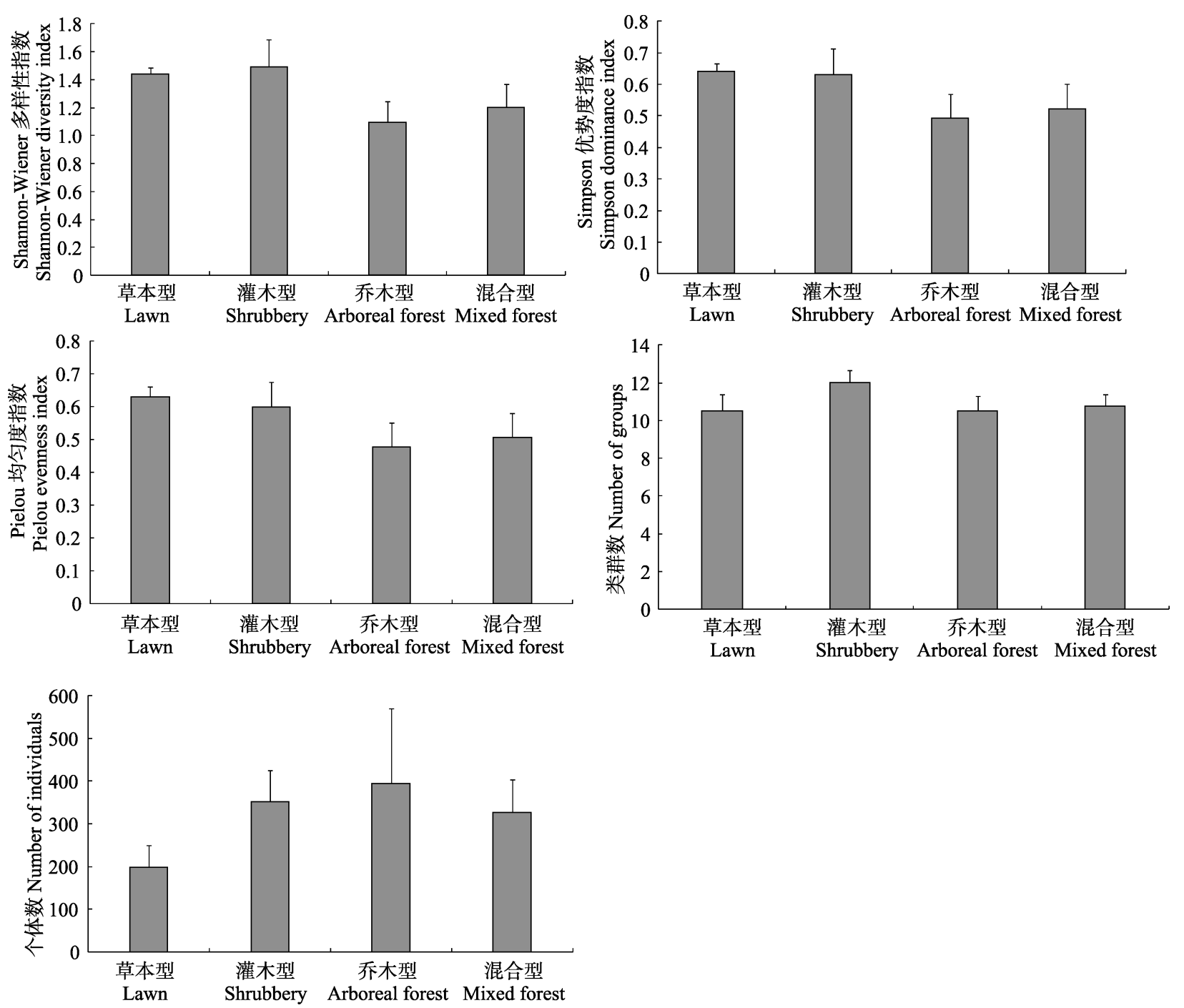

图2 中国科学院奥运村科技园不同绿化带类型深土层动物生态指数(平均值 \pm 标准误)

Fig. 2 Ecological indices of animal communities of deep soil layer in different treelawn type of Olympic Campus of Chinese Academy of Sciences (mean \pm SE)

表4 中国科学院奥运村科技园不同绿化带类型深土层动物 群落相似性指数

Table 4 Jaccard index of animal communities of deep soil layer in different treelawn type of Olympic Campus of Chinese Academy of Sciences

\begin{tabular}{lccc}
\hline $\begin{array}{l}\text { 绿化带类型 } \\
\text { Treelawn }\end{array}$ & $\begin{array}{l}\text { 灌木型 } \\
\text { Shrubbery }\end{array}$ & $\begin{array}{l}\text { 乔木型 } \\
\text { Arboreal forest }\end{array}$ & $\begin{array}{l}\text { 混合型 } \\
\text { Mixed forest }\end{array}$ \\
\hline 草本型 Lawn & 0.79 & 0.83 & 0.75 \\
灌木型 Shrubbery & & 0.83 & 0.75 \\
乔木型 Arboreal forest & & & 0.79 \\
\hline
\end{tabular}

会造成一些类群的数量有所偏差。这也是利用陷阱 类收集器捕获土壤动物的不足之处。

植被为土壤动物提供活动场所和食物来源, 自 然状态下植被类型能显著影响土壤生物多样性和
结构组成(黄旭等, 2010)。如人类干扰较少的上海大 金岛, 3种不同植被类型中, 灌木低矮易形成温暖潮 湿的小环境利于土壤动物群落的聚集, 因而灌木林 多样性更为丰富(靳亚丽等, 2017)。但本文研究结果 显示，各植被类型间的 Shannon-Wiener多样性指 数、Simpson优势度指数和Pielou均匀度指数均无显 著差异，且不同植被类型下土壤动物群落高度相 似。可能是调查地内道路楼房的修建破坏了自然状 态下的土壤结构, 同时密集的人类活动增大了物种 传播概率, 从而导致了土壤动物在城市与自然状态 下的分布规律不同。

土壤本身对外界变化具有良好的缓冲作用，是 个相对稳定的生态系统, 越往深层稳定性越高 
(Smith et al, 2015)。但是由于取样方法的限制, 深层 土壤中的动物群落鲜有研究。浅层土壤中除了节肢 动物外, 线虫动物数量也占较大的比例, 在一些水 分充足的生境甚至超过节肢动物(Wu et al, 2011)。 而在本研究中，深层节肢动物数量所占比例巨大, 远高于其他门的动物, 这可能是节肢动物活动能力 相对较强, 或者是受到调查地本身环境因素的影 响。而55 cm以下更深的土层中的土壤动物由哪些 类群构成, 有待更进一步的研究。此外, 深层土壤 中是否还存在大量的未知物种, 这些物种的存在是 否能对全球物种的估算产生影响, 也是本实验试图 去了解土壤深层动物群落结构组成的原因之一。

本文研究的 “深层土壤中的动物”与尹文英 (1998)院士定义的“土壤动物”概念不同。我们调查 的动物是活动于深层土壤中的无脊椎动物, 它们包 括传统意义上的“土壤动物”, 也包括因外界因素而 进入土壤中的动物。如钩腹蜂(Trigonalyidea)雌蜂将 卵产于叶片上，当卵被叶蜂或鳞翅目幼虫吃掉后， 寄生于幼虫体内, 最后可能会随这些幼虫转移到土 壤中; 跳蚤寄生于某些洞穴类食虫目或啮齿目等动 物身上, 也可能被带入土壤中。以上这些动物, 生 活史没有固定在土壤中度过, 而且对土壤是否能产 生影响也未知, 它们并不属于传统意义上的“土壤 动物”, 但是却能在土壤中活动。

致谢: 感谢中国科学院动物研究所刘宁博士在实验 材料准备中的大力帮助, 本研究的顺利开展还得益 于中国科学院动物研究所满沛、贺旭及北京林业大 学季英超在收集器的制作与埋置以及标本处理方 面的帮助，在此一并表示感谢。

\section{参考文献}

Andre HM, Ducarme X, Lebrun P (2002) Soil biodiversity: Myth, reality or conning. Oikos, 96, 3-24.

Bongers T, Ferris H (1999) Nematode community structure as a bioindicator in environmental monitoring. Trends in Ecology \& Evolution, 14, 224-228.

Chen GX, Song DX (2000) A study on soil animal fauna from warm temperate zone in Xiaolongmen forest areas, Beijing. Chinese Biodiversity, 8, 88-94. (in Chinese with English abstract) [陈国孝, 宋大祥 (2000) 暖温带北京小龙门林 区土壤动物的研究. 生物多样性, 8, 88-94.]

Coleman DC, Whitman WB (2005) Linking species richness, biodiversity and ecosystem function in soil system. Ped- biologia, 49, 479-497.

Decaëns T, Mariani L, Lavelle P (1999) Soil surface macrofaunal communities associated with earthworm casts in grasslands of the eastern plains of Colombia. Applied Soil Ecology, 13, 87-100.

Decaëns T, Jimenéz JJ, Gioia C, Measey GJ, Lavelle P (2006) The values of soil animals for conservation biology. European Journal of Soil Biology, 42, 23-38.

Fu BQ, Chen W, Dong XH, Xing ZM, Gao W (2002) The composition and structure of the four soil macrofaunas in Songshan Mountain in Beijing. Acta Ecologica Sinica, 22, 215-223. (in Chinese with English abstract) [傅必谦，陈卫, 董晓晖, 邢忠民, 高武 (2002) 北京松山四种大型土壤动 物群落组成和结构. 生态学报, 22, 215-223.]

Gibb H, Hochuli DF (2002) Habitat fragmentation in an urban environment: Large and small fragments support different arthropod assemblages. Biological Conservation, 106, 91-100

Huang X, Wen WQ, Zhang J, Yang WQ, Liu Y, Yan BG, Huang YM (2010) Soil faunal diversity under typical alpine vegetation in West Sichuan. Chinese Journal of Ecology, 21, 181-190. (in Chinese with English abstract) [黄旭, 文维全, 张健, 杨万勤, 刘洋, 间帮国, 黄玉梅 (2010) 川西高山 典型自然植被土壤动物多样性. 应用生态学报, 21 , 181-190.]

Jaccard (1912) The distribution of the flora of the alpine zone. New Phytologist, 11, 37-50.

Jin YL, Li BC, Geng L, Bu Y (2017) Soil fauna community in different natural vegetation types of Dajinshan Island, Shanghai. Biodiversity Science, 25, 304-311. (in Chinese with English abstract) [靳亚丽, 李必成, 耿龙, 卜云 (2017) 上海大金山岛不同植被类型下土壤动物群落多样 性. 生物多样性, 25, 304-311.]

Li W, Cui LJ, Zhao XS, Zhang MY, Gao CJ, Zhang Y, Wang YF (2015) Community structure and diversity of soil animals in the Lake Taihu lakeshore wetland. Acta Ecologica Sinica, 35, 944-955. (in Chinese with English abstract) [李 伟，崔丽娟，赵欣胜，张曼胤，高常军，张岩，王义飞 (2015) 太湖岸带湿地土壤动物群落结构与多样性. 生态 学报, 35, 944-955.]

Lin YH, Yang DF, Zhang FD, Wang JX, Bai XL, Wang B (2006) Structure of soil anmial community of oakery litter and fluctuation during leaf litter decomposition. Forest Research, 19, 331-336. (in Chinese with English abstract) [林 英华, 杨德付, 张夫道, 王建修, 白秀兰, 王兵 (2006) 栎林调落层土壤动物群落结构及其在调落物分解中的变 化. 林业科学研究, 19, 331-336.]

Lovei GL, Sunderland KD (1996) Ecology and behavior of ground beetles (Coleoptera: Carabidae). Annual Review of Entomology, 41, 231-256.

López H, Oromí P (2010) A pitfall trap for sampling the mesovoid shallow substratum (MSS) fauna. Speleobiology Notes, 2, 7-11. 
Mckinney ML (2008) Effects of urbanization on species richness: A review of plants and animals. Urban Ecosystems, 11, 161-176.

Peng T, Ouyang ZY, Wen LZ, Zheng H (2006) Characters of soil arthropod community in Haidian District of Beijing. Chinese Journal of Ecology, 25, 389-394. (in Chinese with English abstract) [彭涛, 欧阳志云, 文礼章, 郑华 (2006) 北京市海淀区土壤节肢动物群落特征. 生态学杂志, 25 , 389-394.]

Petersen H, Luxton M (1982) A comparative analysis of soil fauna populations and their role in decomposition processes. Oikos, 39, 288-388.

Pielou EC (1985) Mathematical Ecology. Wiley-Interscience, New York.

Powell JR, Craven D, Eisenhauer N (2014) Recent trends and future strategies in soil ecological research: Integrative approaches at Pedobiologia. Pedobiologia, 57, 1-3.

Rebele F (1994) Urban ecology and special features of urban ecosystems. Global Ecology and Biogeography Letters, 4, 173-187.

Rombke J, Jänsch S, Didden W (2005) The use of earthworms in ecological soil classification and assessment concepts. Ecotoxicology and Environmental Safety, 62, 249-265.

Shannon CE, Weaver W (1949) The Mathematical Theory of Communication. University of Illinois Press, Urbanna.

Simpson EH (1949) Measurement of diversity. Nature, 163, 688.

Smith P, Bustamante M, House JI, Sobocka J, Harper R, Pan GX, West P, Clark J, Adhya T, Rumpel C, Paustian K, Kuikman P, Cotrufo MF, Elliott JA, Mcdowell R, Griffiths RI, Asakawa S, Bondeau A, Jain AK, Meersmans J (2015) Global change pressures on soils from land use and management. Global Change Biology, 22, 1008-1028.

Song YS, Li XW, Li F, Li HM (2015) Influence of different types of surface on the diversity of soil fauna in Beijing Olympic Park. Chinese Journal of Applied Ecology, 26,
1130-1136. (in Chinese with English abstract) [宋英石, 李 晓文, 李锋, 李海梅 (2015) 北京市奥林匹克公园不同地 表类型对土壤动物多样性的影响. 应用生态学报, 26, 1130-1136.]

Wall DH, Bardgett RD, Behan PV (2012) Soil Ecology and Ecosystem Services. Oxford University Press, Oxford.

Wang Y, Wei W, Yang XZ, Chen LD, Yang L (2010) Interrelationships between soil fauna and soil environmental factors in China: Research advance. Chinese Journal of Applied Ecology, 21, 2441-2448. (in Chinese with English abstract) [王移, 卫伟, 杨兴中, 陈利顶, 杨磊 (2010) 我国土壤动 物与土壤环境要素相互关系研究进展. 应用生态学报, 21, 2441-2448.]

Wu T, Ayres E, Bardgett RD (2011) Molecular study of worldwide distribution and diversity of soil animals. Proceedings of the National Academy of Sciences, USA, 108, 17720-17725.

Yin WY (1998) Pictorial Keys to Soil Animals of China. Science Press, Beijing. (in Chinese) [尹文英 (1998) 中国土壤 动物检索图鉴. 科学出版社, 北京.]

Yin XQ (2001) Study on Forest Soil Animals in the Northeast of China. Northeast Normal University Press, Changchun. (in Chinese) [殷秀琴 (2001) 东北森林土壤动物研究. 东 北师范大学出版社, 长春.]

Yuan F (2006) Taxonomy of Hexapoda, 2nd edn. China Agriculture Press, Beijing. (in Chinese) [袁锋 (2006) 昆虫分类 学(第二版). 中国农业出版社, 北京.]

Zhang JE, Qin Z, Li QF (2011) Clustering and ordination of soil animal community under different land-use types. Chinese Journal of Ecology, 30, 2849-2856. (in Chinese with English abstract) [章家恩, 秦钟, 李庆芳 (2011) 不同土地 利用方式下土壤动物群落的聚类与排序. 生态学杂志, 30 , 2849-2856.]

(责任编委：吴东辉 责任编辑：问文杰) 